\title{
Culture of chondrocytes in alginate surrounded by fibrin gel: characteristics of the cells over a period of eight weeks
}

\author{
K F Almqvist, L Wang, J Wang, D Baeten, M Cornelissen, R Verdonk, E M Veys, \\ G Verbruggen
}

\begin{abstract}
Objective-To produce tissue engineered cartilage by human articular chondrocytes in vitro for further use in in vivo manipulations for the treatment of cartilage defects.
\end{abstract}

Methods-Human articular chondrocytes were cultured in $0.5 \%, 1.0 \%$, and $2.0 \%$ of alginate for up to four weeks. The optimal concentration of an alginate matrix for cell replication and for aggrecan synthesis by chondrocytes was determined. DNA content in the different culture conditions was measured after two and four weeks. Aggrecan synthesis rates and accumulation in the surrounding extracellular matrix were assessed by $\left[{ }^{35}\right.$ S $]$ sulphate incorporation after the same periods of culture. To follow the outgrowth of chondrocytes from the alginate beads, chondrocytes were cultured for four weeks in 0.5 or $1.0 \%$ alginate surrounded by 0.25 or $0.5 \%$ fibrin gel. DNA content of each culture was measured after different culture periods. Finally, human chondrocytes in $1.0 \%$ alginate beads were embedded in $0.5 \%$ fibrin gel for eight weeks. Immunohistochemical analysis for aggrecan, type I and II collagen was performed weekly.

Results-At two weeks the DNA content in each culture significantly increased in 0.5 and $1.0 \%$ alginate cultures in comparison with baseline values. This increase continued until week 4 at the three alginate concentrations. Aggrecan synthesis at two weeks was highest in 0.5 and $1.0 \%$ alginate cell cultures. At four weeks aggrecan synthesis rates decreased independently of the alginate concentrations. Aggrecan mainly accumulated in the interterritorial matrix. Proliferation of chondrocytes in alginate and outgrowth of these cells in the surrounding fibrin gel were evident throughout the culture period. The accumulation of aggrecan and type II collagen around the cells, in alginate as well as in fibrin gel, gradually increased over the culture period. Type I collagen appeared after six weeks in alginate and in the surrounding fibrin.

Conclusion-Human chondrocytes proliferate in this culture system, show an outgrowth into the surrounding fibrin, and synthesise a cartilage-like matrix for up to eight weeks.

(Ann Rheum Dis 2001;60:781-790)
Defects in the joint surface can be classified as chondral and osteochondral lesions according to whether or not they penetrate into the subchondral bone. The repair of osteochondral lesions is transient and imperfect. ${ }^{1}$ In these lesions a fibrin clot originates from the bleeding subchondral bone. Into this three dimensional fibrin matrix mesenchymal cells can migrate and produce growth factors. Chondral lesions normally do not heal spontaneously in mature cartilage. ${ }^{23}$ Chondrocytes, synoviocytes, or other cells do not migrate into the chondral lesions in the absence of a pre-existing matrix. ${ }^{3}$ Absence of repair ultimately leads to degenerative changes in the affected joint. ${ }^{1}$

In experimental models attempts have been made to fill chondral lesions with biocompatible matrices, such as fibrin or collagen. ${ }^{34}$ In these conditions cartilage repair obviously depends on the number of cells migrating into the artificial matrix. The extracellular matrix production by the few cells migrating into a chondral lesion is insufficient to restore the defect.

Implantation of autologous ${ }^{5}$ or heterologous ${ }^{46}$ chondrocytes, periosteum, ${ }^{7}$ and perichondrium $^{89}$ has been used to fill chondral defects with a sufficient number of cells required to repair the cartilage. None of these methods has proved to be efficient because the original hyaline cartilage was replaced by fibrocartilaginous tissue which eventually degenerated or was lost during follow up.

Implantation of isolated chondrocytes encapsulated in different artificial scaffolds such as synthetic polymers (carbon fibre, ${ }^{10}$ polylactic acid, and polyglycolic acid ${ }^{11}{ }^{12}$ ) or biological matrices (demineralised bone matrix, ${ }^{13}$ collagen, ${ }^{414}{ }^{15}$ hyaluronan, ${ }^{16}{ }^{17}$ fibrin $^{6}{ }^{18}$ ) for chondral and osteochondral lesions has been reported. The artificial matrices should be biodegradable at the appropriate rate and biocompatible to serve as a scaffold for the colonisation by the cells. The chondrocytes should be able to multiply and maintain their original phenotype with the production of cartilage-specific matrix components such as aggrecan and type II collagen.

In this study the proliferation of human articular chondrocytes and their aggrecan synthesis rates were investigated at different concentrations of highly purified alginate, a linear polysaccharide composed of L-guluronic and D-mannuronic acid linked by $\beta 1,4$ and $\alpha 1,4$ glucoside bonds. Human chondrocytes are known to maintain their original phenotype in this naturally derived matrix in in vitro long 
term cultures. ${ }^{19}$ An optimal aggrecan synthesis and cell proliferation is of crucial importance when considering the healing of cartilage lesions by implantation of chondrocytes in a temporary scaffold.

The phenotypic stability and cell proliferation of human articular chondrocytes cultured in alginate beads surrounded by a cell-free fibrin gel were then investigated over a period of eight weeks. Fibrin gel has been shown to provide sufficient support to chondrocytes, and to enhance cell proliferation and new matrix production, resulting in neochondrogenesis in short term cultures. ${ }^{6} 182021$

These experiments could lead to a possible matrix in the future treatment of cartilage defects.

\section{Material and methods}

ISOLATION OF ARTICULAR CHONDROCYTES Human articular chondrocytes were isolated as described elsewhere, ${ }^{22}{ }^{23}$ with a few modifications. Briefly, human articular cartilage was obtained at necropsy from femoral condyles of different donors within 24 hours of death. All donors had died after a short illness. None of them had received corticosteroids or cytostatic drugs. Visually intact cartilage was harvested and prepared for culture. Cartilage removed from the femoral condyles was diced into small fragments, and the chondrocytes were isolated by sequential enzymatic digestion (hyaluronidase, pronase, and collagenase) of the extracellular matrix as described in detail. ${ }^{24}$

Isolated cells were then centrifuged for 10 minutes at $800 \mathrm{rpm}$, washed three times in Dulbecco's modification of Eagle's medium (DMEM) with 10\% fetal calf serum (FCS), tested for viability (trypan blue exclusion test), and counted. More than $95 \%$ of the cells were usually viable after isolation.

CHONDROCYTE CULTURE IN ALGINATE BEADS Chondrocyte cultures in alginate beads were prepared as described elsewhere ${ }^{25}$ with some modifications. Chondrocytes obtained from a 27 year old woman, a 19 year old man, and a 51 year old man (donors 1, 2, and 3, respectively) were suspended in one volume double concentrated Hanks's balanced salts solution without calcium and magnesium (HBSS; Gibco) and carefully mixed with an equal volume of 1,2 , or $4 \%$ alginate (low viscosity, highly purified alginate from Macrocystis pyrifera; Sigma) in HBSS, autoclaved for 15 minutes. The final cell concentration of chondrocytes was $5 \times 10^{6} / \mathrm{ml}$ in $0.5,1$, or $2 \%$ alginate. The chondrocyte/alginate suspension was then slowly dripped through a 23-gauge needle into a $102 \mathrm{mM}$ calcium chloride solution. The beads were allowed to polymerise for 10 minutes at room temperature. The calcium chloride was then removed, and the beads were washed three times with $0.15 \mathrm{M}$ sodium chloride. The chondrocytes in the alginate beads were cultured in a six well plate with $1 \times 10^{6}$ cells per culture (each well containing 20 alginate beads; \pm 50000 chondrocytes per $10 \mu \mathrm{l}$ bead) in an incubator at $37^{\circ} \mathrm{C}$ under $5 \% \mathrm{CO}_{2}$. Four ml of DMEM with $10 \%$ FCS and $50 \mu \mathrm{g}$ freshly dissolved ascorbate per $\mathrm{ml}$ were then added and replaced three times weekly. All experiments were performed in triplicate.

PROLIFERATION OF CHONDROCYTES IN ALGINATE SURROUNDED BY FIBRIN GEL

Alginate beads were maintained in culture in a fibrin gel in order to follow the proliferation of chondrocytes in the beads and outgrowth of these cells into the surrounding fibrin. A 5\% fibrinogen solution containing 3000 Kallidinogenase Inhibitor Units of the fibrinolysis inhibitor aprotinin per $\mathrm{ml}$ (Tissucol; Immuno AG, Vienna, Austria) was diluted to $0.5 \%$ and $0.25 \%$ with HBSS. The fibrinogen solution was stirred until the fibrinogen was dissolved.

Chondrocytes from two donors, a 37 year old man and a 62 year old woman (donors 4 and 5 ), were encased in 0.5 or $1.0 \%$ alginate. Two hundred $\mu \mathrm{l}$ of $1.0 \%$ alginate beads was then immersed in $300 \mu 10.25$ or $0.5 \%$ fibrinogen solution, and $200 \mu \mathrm{l}$ of the $0.5 \%$ beads was placed in $300 \mu \mathrm{l} \quad 0.25 \%$ fibrinogen. The fibrinogen was allowed to gel by adding $100 \mu \mathrm{l}$ of a $100 \mathrm{IU} / \mathrm{ml}$ thrombin solution dissolved in $4.44 \mathrm{mg} / \mathrm{ml} \mathrm{CaCl}_{2}$. Before application this thrombin solution was warmed to $37^{\circ} \mathrm{C}$. It took one minute for the fibrinogen to form a fibrin gel. DMEM $(1.5 \mathrm{ml})$ with $10 \%$ of FCS and 50 $\mu \mathrm{g} / \mathrm{ml}$ of freshly dissolved ascorbate were used as nutrient medium and replaced three times weekly. One batch of chondrocytes from donors 4 and 5 was also cultured in $0.5 \%$ fibrin. Colonisation of the alginate/fibrin matrix was followed by DNA measurements.

ACCUMULATION OF EXTRACELLULAR MATRIX BY CHONDROCYTES CULTURED IN ALGINATE SURROUNDED BY FIBRIN GEL

Chondrocytes cultures were made in $1.0 \%$ alginate surrounded by $0.5 \%$ fibrin gel as described above. The deposition of aggrecan, type II and I collagen by the chondrocytes in the alginate/fibrin matrix was stained by immunohistochemistry. A series of cultures from a 53 year old man (donor 6) was started and at different times (3 days, 1, 2, 3, 4, 6, and 8 weeks) one culture was either mounted in Jung tissue freezing medium (Leica Instruments, Nussloch, Germany) and stored at $-80^{\circ} \mathrm{C}$, until used for further cryosections with immunohistochemistry, or embedded in paraffin for light microscopy.

\section{${ }^{35}$ S LABELLED AGGRECAN SYNTHESIS BY CHONDROCYTES IN ALGINATE BEADS}

Radioactive label $(10 \mu \mathrm{Ci} / \mathrm{ml})$ was included in the incubation medium of the alginate beads during the last 48 hours of weeks 2 and 4 of culture. The medium of the cultures was then aspirated and the alginate beads were washed and dissolved in $3 \mathrm{ml}$ of $55 \mathrm{mM}$ sodium citrate $\mathrm{pH} 6.8,0.15 \mathrm{M} \mathrm{NaCl}$ at $25^{\circ} \mathrm{C}$ for 10 minutes. The resulting suspension was centrifuged at $900 \mathrm{rpm}$ for 10 minutes to separate cells with their cell associated matrix (CAM - the pel$\mathrm{let}^{26}$ ) from the constituents of the interterritorial matrix (ITM - the supernatant). The aggrecans of the CAM were further extracted 
by incubation for 48 hours in dissociative conditions with $4 \mathrm{M} \mathrm{GuHCl}$ in a $50 \mathrm{mM}$ sodium acetate buffer $\mathrm{pH} 5.8,{ }^{27}$ at $4^{\circ} \mathrm{C}$ in the presence of proteinase inhibitors: $0.1 \mathrm{M} \varepsilon$-amino-ncaproic acid, $0.01 \mathrm{M}$ EDTA, $0.005 \mathrm{M}$ benzamidine chloride, and $0.01 \mathrm{M}$ phenylmethylsulphonyl fluoride. ${ }^{28}$ This solution was subsequently centrifuged for 10 minutes at $1000 \mathrm{rpm}$ and the dissociated CAM aggrecans were recovered in the supernatant. The suspensions obtained (CAM and ITM) and the nutrient media were stored separately at $-20^{\circ} \mathrm{C}$ for further analysis.

Spent culture media, CAM and ITM solutions were desalted using gel permeation chromatography through Sephadex G25 gels (Pharmacia, Uppsala, Sweden) in $0.067 \mathrm{M}$ phosphate $\left(\mathrm{K}_{2} \mathrm{HPO}_{4} / \mathrm{Na}_{2} \mathrm{HPO}_{4}\right)$ pH 6.8, containing $0.01 \mathrm{M} \mathrm{Na} \mathrm{SO}_{4}$ to separate the ${ }^{35} \mathrm{~S}$ labelled aggrecans from free $\left[{ }^{35} \mathrm{~S}\right]$ sulphate $\left({ }^{35} \mathrm{SO}_{4}\right)$. The eluted macromolecular fractions were counted for radioactivity. The radioactivity under the curves was related to the total incorporation of ${ }^{35} \mathrm{SO}_{4}$ in aggrecans by the respective cultures. Aggrecan synthesis was expressed as $\mathrm{pg} \mathrm{SO}_{4}$ incorporated into aggrecans per $1 \times 10^{6}$ chondrocytes per hour. ${ }^{29}$

DNA MEASUREMENT

Chondrocyte proliferation in the different culture conditions was followed by measurement of the DNA content in the chondrocyte cultures. Initially, each culture contained approximately $1 \times 10^{6} \pm 50000$ chondrocytes. From each donor three cultures were stored at $-20^{\circ} \mathrm{C}$ at day 1 after having been placed in culture (start value), and after two and four weeks. DNA content in each culture was assayed as described $^{30}$ using the enhancement of fluorescence of trisbenzimidazole (Hoechst 33258; Pharmacia Biotech Inc, San Francisco, CA, USA) when it binds to double stranded DNA. ${ }^{31}$

The alginate cultures were dissolved by adding $3 \mathrm{ml}$ of $55 \mathrm{mM}$ sodium citrate, $\mathrm{pH}$ 6.8. The alginate cultures surrounded by a fibrin gel were dissolved by incubation with $100 \mathrm{mg} / 100$ $\mathrm{ml}$ trypsin (Sigma) and $20 \mathrm{mg} / 100 \mathrm{ml}$ EDTA (UCB, Leuven, Belgium) in sodium citrate at $37^{\circ} \mathrm{C}$ for 24 hours. The solutions obtained were further sonicated for 30 seconds (MSE ultrasonicator, type 5.65; power set at $100 \mathrm{~W}$ ). One and a half $\mathrm{ml}$ of the solubilised alginate or alginate/fibrin cultures was added to $1.5 \mathrm{ml}$ of the Hoechst dye solution, and fluorescence was measured in a Hoefer dynaquant 200 fluorometer (Hoefer Pharmacia Biotech Inc), with double stranded calf thymus DNA (Sigma) in phosphate buffered saline (PBS) as a standard. The emission was measured at $460 \mathrm{~nm}$ for an excitation wavelength of $365 \mathrm{~nm}$.

\section{IMMUNOHISTOCHEMISTRY}

The alginate/fibrin cultures were mounted in Jung tissue freezing medium. Frozen sections of $30 \mu \mathrm{m}$ were layered on Star Frost glass slides (Knittelgläser, Braunschweig, Germany) and used for immunohistochemistry. The sections were fixed for 10 minutes in acetone and incubated for 30 minutes with the following mouse antihuman monoclonal antibodies
(mAbs): anti-aggrecan (clone 969D4D11; Biosource Europe SA, Nivelles, Belgium), anti-type I collagen (clone I-8H5; ICN Biomedicals, Aurora, USA), and anti-type II collagen (clone II-4C11; ICN Biomedicals). Final dilutions were $1: 50,1: 100$, and $1: 100$ of $1 \mathrm{mg} / \mathrm{ml}$ for aggrecan, type I and type II collagen, respectively. Before incubation with the mouse $\mathrm{mAb}$ for type I and II collagen, the sections were incubated with $2500 \mathrm{IU} / \mathrm{ml}$ hyaluronidase (bovine testicular hyaluronidase VI-S; Sigma) in PBS for 40 minutes at $37^{\circ} \mathrm{C}$ to expose the appropriate epitopes. ${ }^{32}$ Parallel sections were incubated with irrelevant isotype matched $\mathrm{mAb}$ as a negative control. After incubation with the $\mathrm{mAb}$, the cryosections were rinsed with PBS and endogenous peroxidase was blocked with $1 \%$ hydrogen peroxide in distilled water. The sections were subsequently incubated for 15 minutes with a biotinylated antimouse secondary antibody, followed by 15 minutes with a streptavidin-peroxidase complex (LSAB+ Kit, Dako, Glostrup, Denmark). The colour reaction was developed with 3-amino-9-ethylcarbazole substrate (Dako) as chromogen. Finally, the sections were counterstained with haematoxylin. All incubations were carried out at room temperature and the sections were washed with PBS between all steps. Isotype matched immunostaining was performed on cryosections of normal human skin and cartilage to confirm specificity of the antibodies. The mAbs for type II collagen and aggrecan specifically stained the cartilage, whereas the mAb for type I collagen stained the dermis.

Counting of cell nuclei was performed in one microscopic field. The ratio of positive staining cells for the above mentioned mAbs to the total cell number was determined.

\section{STATISTICS}

All experiments (aggrecan synthesis rates, DNA measurement, and ratio of positive staining cells for a given epitope) were carried out threefold. Mean values and one standard deviation (SD) were calculated. Statistical analysis was carried out by the unpaired two tailed Student $t$ test to determine whether variables were significantly different $(p<0.05)$ in the respective experiments.

\section{Results}

PROLIFERATION OF CHONDROCYTES AT DIFFERENT CONCENTRATIONS OF ALGINATE AT DIFFERENT POINTS OF TIME

At two weeks DNA content in each culture was significantly higher than at day 1 when chondrocytes were cultured in $0.5 \%$ alginate. This increase in proliferation, though less pronounced, was also seen in the 1.0 and $2.0 \%$ alginate cultures at two weeks. After four weeks in culture a significant increase in cell proliferation was seen at the three different alginate concentrations (fig 1).

PROLIFERATION OF CHONDROCYTES CULTURED IN ALGINATE BEADS SURROUNDED BY FIBRIN GEL At two weeks DNA content in each culture was significantly increased in the four different culture conditions (table 1). An increase of $29 \%$, 

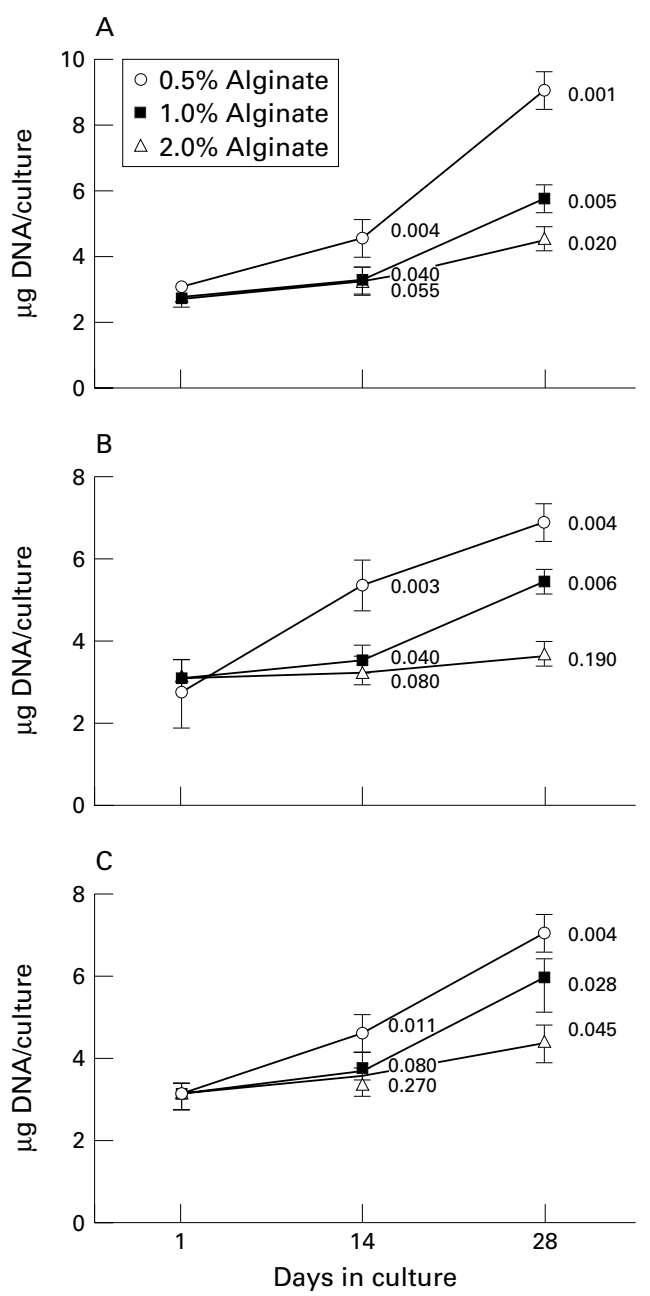

Figure 1 DNA content in each culture from donor 1 (A), 2 (B), and $3(C)$ was investigated at day 1, and at two and four weeks. Data are presented as mean values of three cultures; standard deviations and $p$ values are given.

$24 \%, 33 \%$, and $17 \%$ for donor 4 and of $27 \%$, $38 \%, 43 \%$, and $22 \%$ for donor 5 was seen in the $1.0 \%$ alginate surrounded by $0.5 \%$ fibrin gel, the $1.0 \%$ alginate cultures surrounded by $0.25 \%$ fibrin gel, the $0.5 \%$ alginate surrounded by $0.25 \%$ fibrin gel, and in the chondrocytes cultured as a suspension in $0.25 \%$ fibrin gel, respectively. DNA content in each culture was not significantly different between the four culture conditions at two weeks.

Table 1 Human chondrocytes cultured in alginate surrounded by fibrin gel. DNA measurement over a period of four weeks

\begin{tabular}{lllll}
\hline & & \multicolumn{2}{l}{ DNA measurement } \\
\cline { 3 - 5 } & Alginatelfibrin & 1 Day & 2 Weeks & 4 Weeks \\
\hline Donor 4 & $1.0 / 0.50$ & $5.86(9.6)$ & $7.27(1.9)$ & $14.30(5.9)$ \\
M37 & $1.0 / 0.25$ & $5.54(7.1)$ & $7.37(4.0)$ & $11.64(0.1)$ \\
M37 & $0.5 / 0.25$ & $5.80(8.0)$ & $7.48(2.4)$ & $12.18(2.7)$ \\
M37 & -10.25 & $5.41(5.2)$ & $6.33(2.0)$ & $8.12(10.8)^{\star}$ \\
Donor 5 & $1.0 / 0.50$ & $5.43(1.5)$ & $7.48(2.4)$ & $11.49(4.0)$ \\
F62 & $1.0 / 0.25$ & $5.32(3.8)$ & $7.60(3.3)$ & $10.04(2.2)$ \\
F62 & $0.5 / 0.25$ & $5.47(1.1)$ & $6.93(2.5)$ & $10.81(3.2)$ \\
F62 & -10.25 & $5.49(1.6)$ & $6.70(3.3)$ & $8.34(2.2)^{\star}$ \\
\hline
\end{tabular}

Donors 4 and 5 are presented. Alginate/fibrin: concentration of alginate (\%) and of surrounding fibrin gel (\%). DNA content in each culture ( $\mu \mathrm{g}$ DNA/culture) was investigated at day 1 , and at weeks 2 and 4 . Mean values (triplicate cultures) are given; coefficient of variation in brackets.

${ }^{\star}$ Significant difference $(<0.05)$ when compared with the other three culture conditions at four weeks.

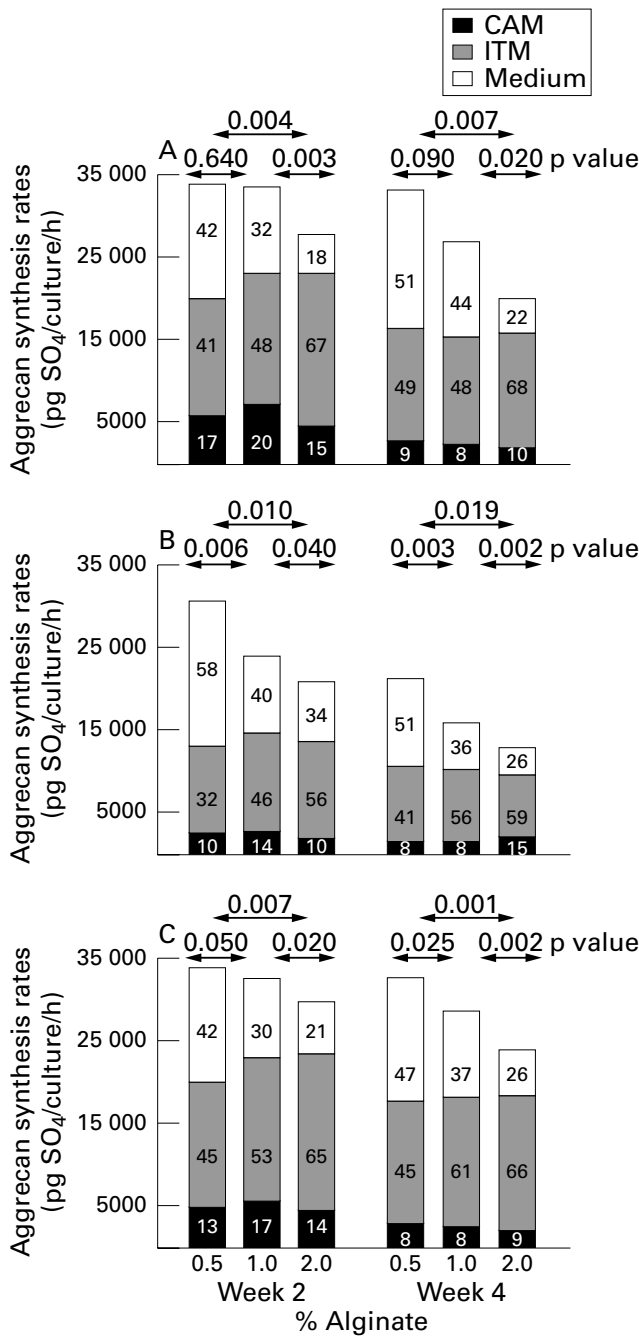

Figure 2 Total aggrecan synthesis rates per culture from donor $1(A), 2(B)$ and $3(C)$ at two and four weeks in three different concentrations of alginate are given, with the relative amounts of the newly synthesised aggrecans in cell associated matrix (CAM), interterritorial matrix (ITM), and medium related to the total aggrecan synthesis

(percentage value in column). Data are presented as mean values of three cultures $p$ values $(0.5 \% \mathrm{v} 1.0 \%, 1.0 \% \mathrm{v}$

$2.0 \%$, and $0.5 \% v 2.0 \%$ ) at two and four weeks are given. The $p$ values for aggrecan synthesis rates between two and four weeks are 0.27, 0.02, and 0.0003 for donor $1,0.0004$, 0.0006 , and 0.006 for donor 2 , and $0.31,0.10$, and 0.04 for donor 3 in $0.5 \%, 1.0 \%$, and $2.0 \%$ alginate cultures, respectively.

At four weeks cell proliferation was more pronounced than at two weeks. Compared with the start values DNA content in each culture was increased by $101 \%, 144 \%, 110 \%$, and $50 \%$ for donor 4 and by $98 \%, 112 \%, 89 \%$, and $57 \%$ for donor 5 in the respective culture conditions. When the four culture conditions at four weeks were compared, cell proliferation was significantly more pronounced in the cultures where chondrocytes were cultured in alginate beads surrounded by fibrin gel.

AGGRECAN SYNTHESIS AT DIFFERENT CONCENTRATIONS OF ALGINATE AT TWO AND FOUR WEEKS

Figure 2 shows total aggrecan synthesis (CAM, ITM plus medium) at two and four weeks. 
At two weeks the total aggrecan synthesis was most pronounced in $0.5 \%$ alginate cultures, though a significant difference with the $1.0 \%$ alginate cultures was not found in donors 1 and 3. At this time most of the newly synthesised aggrecan was retained in the ITM in the 1.0 and $2.0 \%$ alginate cultures. A major portion of the aggrecans diffused into the medium in the $0.5 \%$ alginate cultures at two weeks. The diffusion of newly synthesised aggrecans in the nutrient medium was less pronounced in higher concentrated alginate gels. The CAM contained $10-20 \%$ of the newly synthesised aggrecan at two weeks in the three culture conditions.

At four weeks the total aggrecan synthesis rates in $0.5 \%$ alginate cultures remained most pronounced. A decrease in aggrecan synthesis rates was seen in all $2.0 \%$ alginate cultures and in two of three donors for $1.0 \%$ alginate cultures. The proportion of newly synthesised aggrecan retained in the ITM remained most important in 1.0 and $2.0 \%$ alginate cultures. Absolute and relative amounts of newly synthesised aggrecans in the nutrient media decreased with increasing concentration of alginate. Absolute and relative amounts of newly synthesised aggrecans retained in the CAM showed a tendency to decrease in the four week cultures at the three alginate concentrations used.

Because the DNA proliferation and aggrecan synthesis rates were determined on cultures from the same donors (donors 1-3), ${ }^{35} \mathrm{SO}_{4}$ incorporation per $\mu \mathrm{g}$ DNA could be calculated (fig 3). No consistent differences were found between the three alginate concentrations used, either at two weeks or at four weeks. The aggrecan synthesis rates for each cell were decreased after four weeks in culture in comparison with two weeks.

IMMUNOHISTOCHEMISTRY OF LONG TERM CULTURES OF CHONDROCYTES IN ALGINATE SURROUNDED BY FIBRIN GEL

From the start of the cultures a marked presence of positive staining cells for aggrecan in alginate was seen (fig 4A). The staining was pericellular, close to the cell. In the surrounding fibrin gel some cells were already present, though no staining for aggrecan was seen in this matrix after three days of culture. The number of positive staining cells for aggrecan in alginate increased progressively during the first two weeks in culture. From then on the number of positive cells remained rather constant (table 2). The extracellular staining became slightly more profuse in the intercellular matrix. Positive cells in the surrounding fibrin gel appeared at two weeks (fig 4B). At this time aggrecans were mainly seen in the immediate surroundings of the cells. At four weeks aggrecan staining became pronounced in the distant matrix (fig 4C). At eight weeks a diffuse deposition of aggrecan could be detected throughout both artificial matrices (fig $4 \mathrm{D})$. The alginate scaffold was poorly preserved during histological processing of the cryosections. The maintenance of the alginate gel with newly synthesised aggrecans in the
CAM and in the ITM could be seen in paraffin sections (fig 5).

Type II collagen appeared progressively over the first weeks in culture, as shown in table 2 and figs $4 \mathrm{~A}$ and $\mathrm{B}$. The staining was seen close to the cell (figs $4 \mathrm{~A}$ and B). Type II collagen deposition in the ITM in alginate could hardly be seen during the eight week culture owing to a problem with processing the cryosections. In the fibrin gel the ITM and the CAM were diffusely stained with increasing numbers of positively stained cells (fig 4C). At eight weeks,

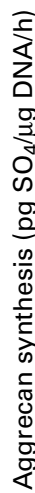

ב
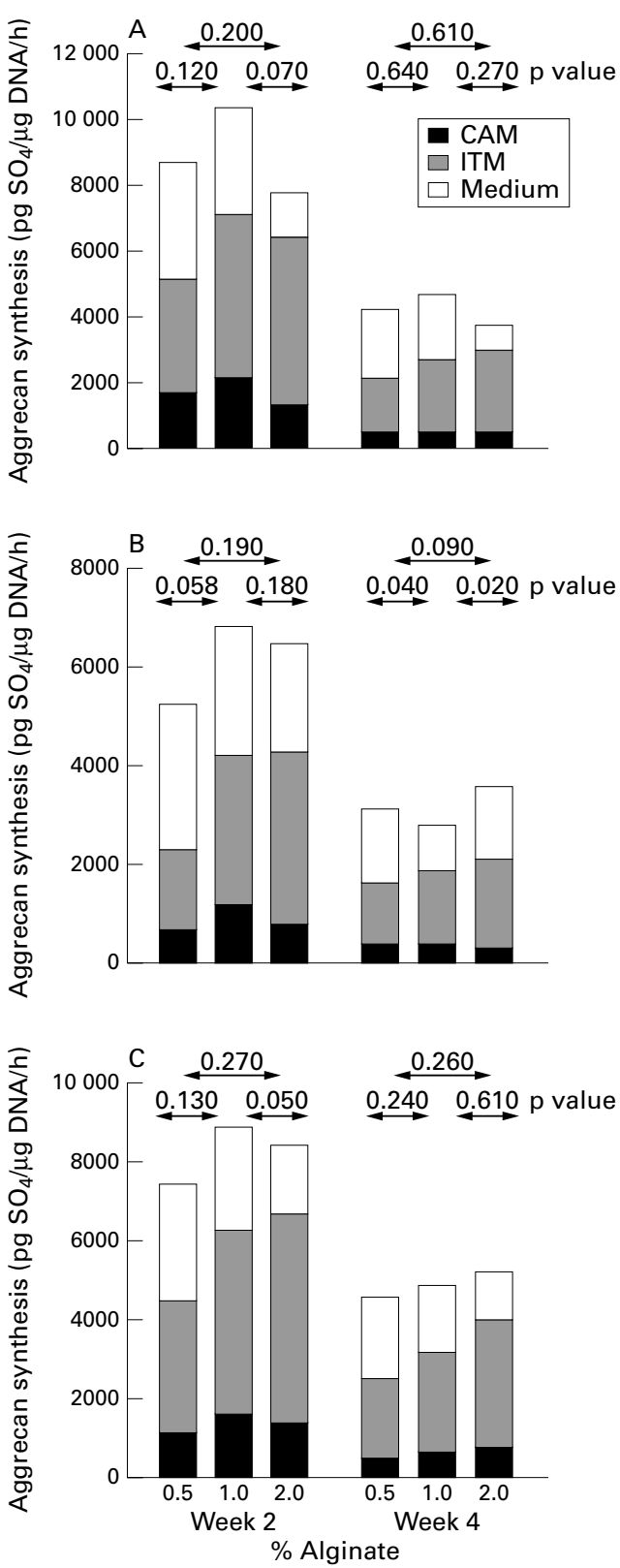

Figure 3 Total aggrecan synthesis rates for each cell from donor $1(A), 2(B)$, and $3(C)$ at two and four weeks in three different concentrations of alginate are given. The relative amounts of the newly synthesised aggrecans in cell associated matrix (CAM), interterritorial matrix (ITM), and medium related to the total aggrecan synthesis rates for each cell are identical to those in fig 2. Data are presented as mean values of three cultures. $p$ Values $(0.5 \% \mathrm{v} 1.0 \%$, $1.0 \% v 2.0 \%$, and $0.5 \%$ v $2.0 \%$ ) at two and four weeks are given. The $p$ values for aggrecan synthesis rates between two and four weeks are $<0.05$ in all alginate concentrations for the three donors. 
A

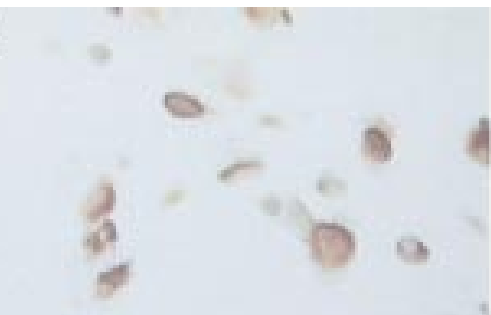

Anti-aggrecan in alginate

Anti-aggrecan in fibrin

\section{Anti-collagen II in fibrin}

\section{Anti-collagen I in fibrin}

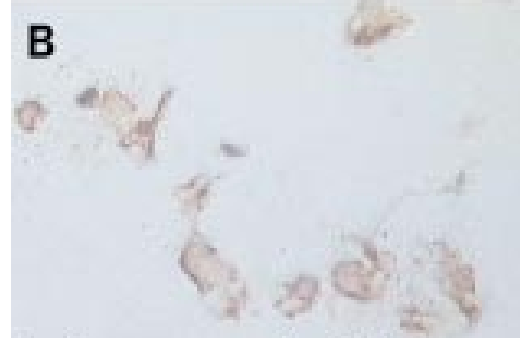

Anti-aggrecan in alginate
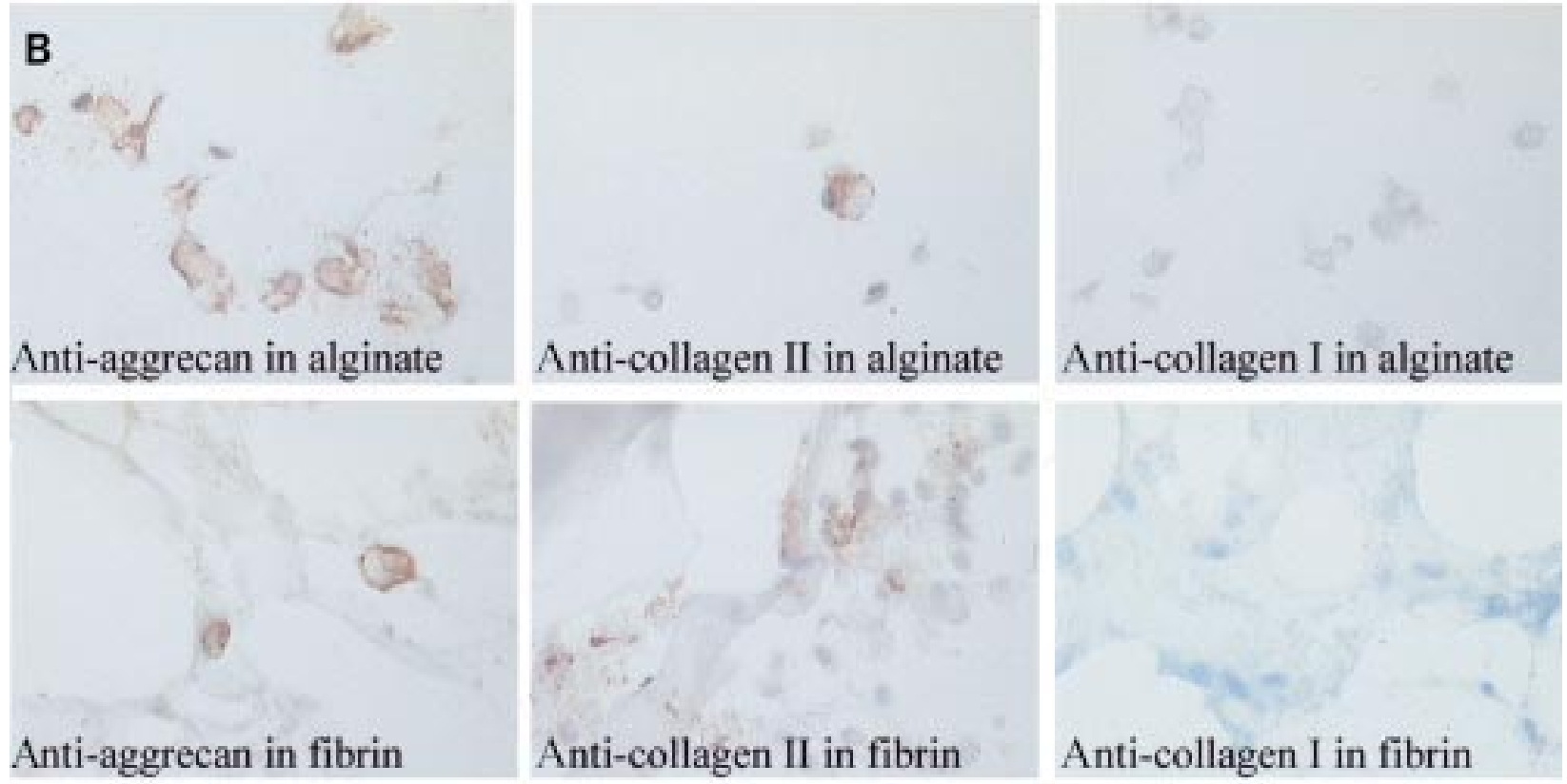

Figure 4 Immunohistochemistry of chondrocytes cultured in alginate surrounded by fibrin gel. Staining of aggrecan, type II collagen, and type I collagen in alginate and fibrin at three days (A), two weeks (B), four weeks (C), and eight weeks (D). Magnification $\times 100$.

$72 \%$ of the cells in the fibrin gel were stained for type II collagen, with a marked staining of the intercellular matrix (fig 4D).

In the alginate gel as well as in the fibrin gel, less collagen staining was present for type I collagen than for type II collagen and aggrecan (table 2). A slight pericellular staining in the alginate and in the fibrin was seen from weeks 2 to 3 onwards (fig 4 C). Percentages of positive staining cells increased to $21 \%$ in the alginate and to $9 \%$ in the fibrin gel at eight weeks of culture (fig 4D).

\section{Discussion}

Natural repair of chondral and osteochondral lesions in adult mammals does not occur. ${ }^{13}$ These lesions initiate degenerative changes of the affected joint. A valuable technique to restore a defect in the articular surface is still non-existent. Various surgical techniques have been reported in animals and in humans, such as abrasion techniques, ${ }^{33}$ microfracturing, ${ }^{34}$ slurry grafting, ${ }^{35}$ periosteal, ${ }^{8}$ perichondral, ${ }^{9}$ and osteochondral grafting, ${ }^{36-38}$ stem cell $^{39}$ or chondrocyte $^{640}$ transplantation. The short term clinical results of some of these techniques have been promising, though microscopic evidence that the repair tissue consists of hyaline cartilage instead of fibrocartilaginous tissue has not been obtained. Extensive studies of chondrocyte metabolism and behaviour in different situations and matrices will provide the necessary knowledge to achieve optimal repair of cartilage tissue. At present, tissue 

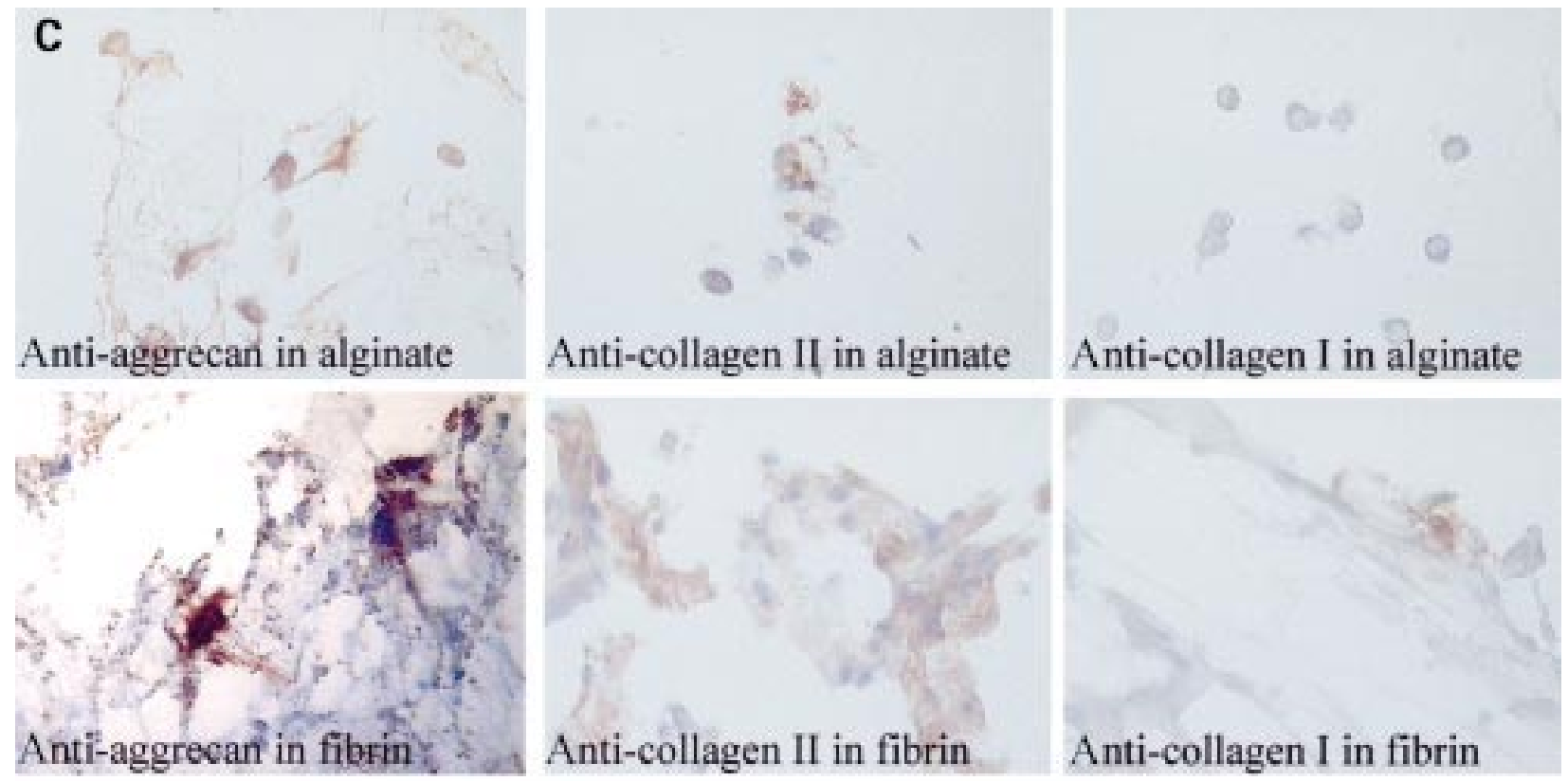

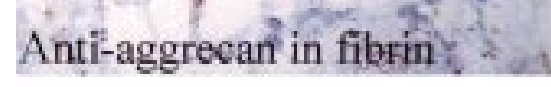

\section{Anti-collagen II in fibrin}

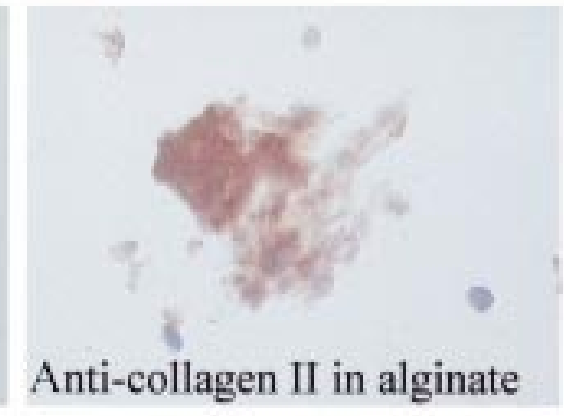

\section{Anti-aggrecan in alginate}

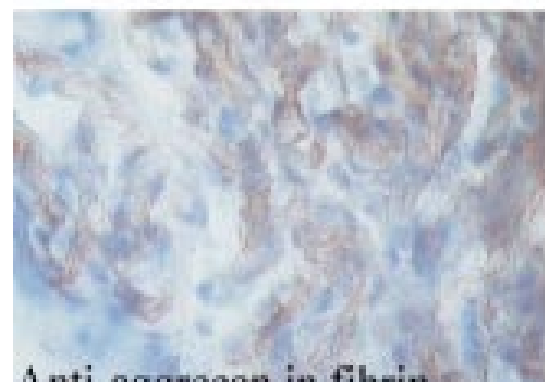

\section{Anti-aggrecan in fibrin}

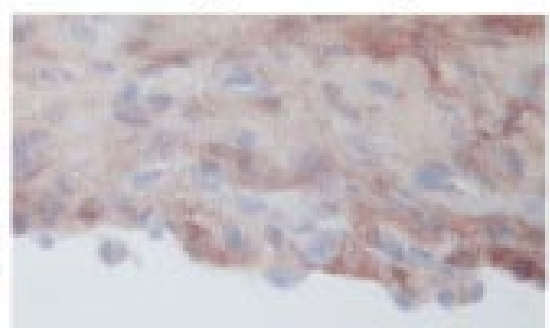

Anti-collagen II in fibrin

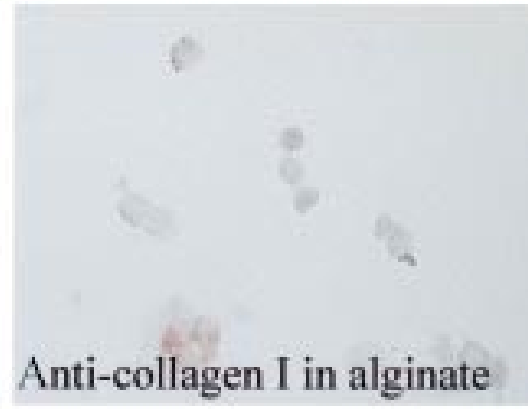

Anti-collagen I in fibrin engineering of cartilage seems promising. Autologous or allogenous chondrocytes have been cultured in biodegradable and biocompatible three dimensional matrices, where they proliferate and synthesise an extracellular matrix containing cartilage-specific molecules

Table 2 Immunocytostaining of chondrocytes in alginate/fibrin cultures: percentage of positive cells

\begin{tabular}{|c|c|c|c|c|c|c|}
\hline & \multicolumn{2}{|l|}{ Aggrecan } & \multicolumn{2}{|c|}{ Type II collagen } & \multicolumn{2}{|c|}{ Type I collagen } \\
\hline & Alginate & Fibrin & Alginate & Fibrin & Alginate & Fibrin \\
\hline 3 Days & $49(7)$ & $1(90)$ & $0(-)$ & $0(-)$ & $0(-)$ & $0(-)$ \\
\hline 1 Week & $84(3)$ & $24(12)$ & $11(16)$ & $9(13)$ & $0(-)$ & $0(-)$ \\
\hline 2 Weeks & $92(3)$ & $30(7)$ & $15(15)$ & $12(13)$ & $10(21)$ & $2(60)$ \\
\hline 3 Weeks & 90 (3) & $30(6)$ & $23(7)$ & $16(13)$ & $15(14)$ & $2(60)$ \\
\hline 4 Weeks & $90(2)$ & $31(7)$ & $22(10)$ & $20(10)$ & $12(10)$ & $5(10)$ \\
\hline 6 Weeks & $94(3)$ & $29(6)$ & $32(9)$ & $41(6)$ & $20(8)$ & $9(19)$ \\
\hline 8 Weeks & $92(1)$ & $33(4)$ & $5(3)$ & $72(4)$ & $21(14)$ & $9(24)$ \\
\hline
\end{tabular}

Mean of positive staining cells from donor 6 is given; coefficient of variation in brackets. such as aggrecan and collagen type II. Implantation of isolated chondrocytes in collagen, hyaluronan, and fibrin matrices for the treatment of cartilage defects has been performed. ${ }^{4615-17}$ Although none of these matrices offers mechanical stability just after their implantation, they gradually become populated by cells which produce an extracellular matrix that allows the scaffold to become more resistant to tensile and compressive forces. ${ }^{13152041}$ Our study focused on the suitability of alginate gel as a vehicle for chondrocyte transplantation.

One of the advantages of alginate is the possibility of investigating the different intercellular compartments surrounding the chondrocytes in vitro: the CAM and the ITM. ${ }^{42}$ Newly synthesised aggrecans spend only a short time in the CAM with a higher rate of aggrecan 


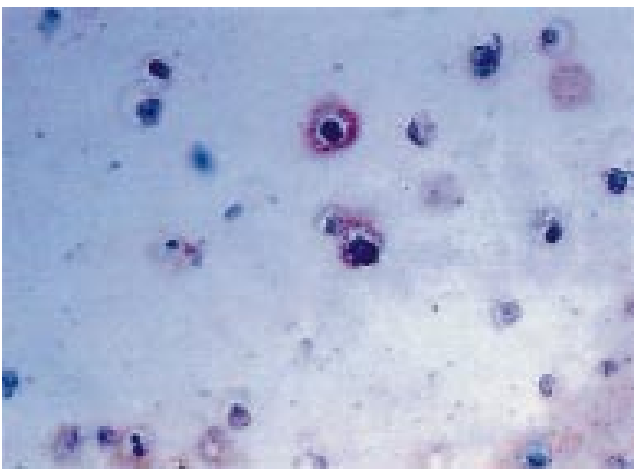

Figure 5 Paraffin section of chondrocytes cultured in alginate beads for two weeks and stained for aggrecan. A well defined cell associated matrix with newly synthesised aggrecans can be seen, as well as a slighter staining of the intercellular matrix. Magnification $\times 100$.

turnover than in the ITM, making the CAM more biologically active. ${ }^{43}$ The ITM forms the largest domain of the intercellular matrix. The alginate matrix is biocompatible and biodegradable. $^{44-47}$

Cell replication was most prominent at the lowest alginate concentration. Aggrecan synthesis rates (for each cell) were not influenced by the concentration of the alginate, but the chondrocytes decreased their aggrecan synthesis rates over time, probably as a response to the increasing accumulation of matrix components.

Overall aggrecan synthesis per mass unit of alginate was affected by the concentration of the gel. Increasing total ${ }^{35} \mathrm{~S}$ incorporation rates reflected increasing cell numbers at decreasing alginate concentrations. However, the lower the alginate content in the beads the more newly synthesised aggrecans escaped from the gel, and this ${ }^{35} \mathrm{~S}$ material was recovered in the nutrient media.

The consistent proliferation of the chondrocytes in 0.5 and $1 \%$ alginate gels and a better equilibrium between immobilisation and escape of newly formed extracellular matrix products in the 1 and $2 \%$ alginate gels made us choose $1 \%$ of alginate for further experiments. Furthermore, handling and manipulation of $0.5 \%$ alginate without damaging the beads was difficult. The synthesis and accumulation of aggrecans per mass unit of alginate is a more relevant parameter because similar events will occur in a future implant.

Chondrocytes were then cultured in alginate beads surrounded by a fibrin gel for a period of eight weeks. Fibrin gel is malleable, biodegradable, and biocompatible. ${ }^{6}{ }^{18}$ When used in an implantation procedure it would permit the temporary scaffold to adhere to the edges of the cartilage lesion, allowing transplant integration. ${ }^{48}$ During the eight week culture period an outgrowth from the alginate beads into the surrounding fibrin gel was seen. In vitro outgrowth of chondrocytes from alginate beads into the surrounding nutrient medium has been reported, with the formation of a monolayer in the culture dishes after some weeks. ${ }^{50}$ Neither the alginate content of the beads nor the concentrations of fibrin gel influenced the outgrowth from the beads or the colonisation of the surrounding fibrin matrix over a four week period. Fibrin gel has been used as a matrix for chondrocytes in in vitro ${ }^{18}$ and in vivo $^{651}$ experiments. The cells proliferate and synthesise an extracellular matrix resembling hyaline cartilage as long as the cells are surrounded by fibrin. ${ }^{18}$ Subcutaneously implanted fibrin containing allogeneic chondrocytes in nude mice has been shown to stimulate cell proliferation, cell migration, and matrix synthesis, forming neocartilaginous tissue. ${ }^{20}$ Conversely, fibrin gel used as a temporary scaffold for chondrocytes in osteochondral lesions in sheep did not show much resemblance to hyaline cartilage after one year, though the authors questioned the histological criteria used in their study. ${ }^{6}$

A disintegration of fibrin gel has been reported, though this might be influenced by a fibrinolysis inhibitor-for example, aprotinin, by increasing the concentration of fibrinogen or by using an optimal concentration of chondrocytes per ml. ${ }^{21}{ }^{47}$ We found that the fibrin did not dissolve over a period of eight weeks, so that chondrocytes migrating from the alginate into the fibrin remained surrounded by a matrix. Immunohistochemistry showed a strong presence of cells staining for aggrecan and type II collagen in alginate from one week up to eight weeks, and a progressive increase of outgrowing aggrecan and type II positive cells in the surrounding fibrin gel. Staining for both extracellular matrix compounds also showed diffusion of the newly synthesised molecules into the surrounding matrix. This was less apparent in alginate than in fibrin because during the washing and staining procedures of the cryosections, the integrity of the alginate matrix was not maintained. The intercellular space was better conserved in paraffin sections.

It was concluded that a neosynthesis of a cartilage-like matrix over a short period in in vitro culture of human articular chondrocytes had occurred in this culture system. Immunostaining showed the presence of slight amounts of type I collagen (up to $21 \%$ staining cells in alginate and $9 \%$ in fibrin) after 6-8 weeks in culture. In vitro culture periods of 6-12 months are necessary to mimic a repair as seen in cartilage lesions in rabbits, guineapigs, and other animals. To have the same repair mechanism as seen in humans an even longer in vitro culture period is probably useful. This culture period is not feasible in practice.

The two matrices described above allow the diffusion of macromolecules and other nutrient factors necessary for cell viability, proliferation, and extracellular matrix synthesis. ${ }^{52}$

Autologous chondrocytes for cartilage repair in humans are currently used in operative techniques. A limitation in the number of autologous chondrocytes available for these procedures, the dedifferentation during ex vivo propagation of the cells necessary to reach a sufficient number of cells, and the need for repeated surgery explain the interest in the transplantation of allogeneic chondrocytes, possibly obtained from a "tissue bank". The results of this study show the feasibility of in 
vitro proliferation and synthesis of a cartilagelike matrix by human chondrocytes in bioengineered tissue. Tissue engineered cartilage by chondrocytes cultured in alginate has been reported. ${ }^{4153}$ In these studies the biocompatibility of the gel was confirmed, though the experiments were performed on athymic mice in a vascular region. If alginate containing chondrocytes is placed in vascular tissue in animals with a normal immune system an immunological response would be expected. When it is used for repair of cartilage defects, immune or inflammatory responses are unlikely because of the avascular properties of this tissue.

The authors thank Carine Broddelez and Jenny Vermeersch for their invaluable technical expertise.

Grants: Bijzonder Onderzoeks Fonds: project No 011D2698; Fonds voor Wetenschappelijk Onderzoek: project No 3G13201.

1 Shapiro F, Koide S, Glimcher MJ. Cell origin and differentiation in the repair of full-thickness defects of articular cartilage. J Bone Joint Surg Am 1993;75:532-53.

2 Mankin HJ. The reaction of articular cartilage to injury and osteoarthritis. N Engl J Med 1974;291:1285-92.

3 Hunziker EB, Rosenberg LC. Repair of partial-thickness defects in articular cartilage: cell recruitment from the
synovial membrane. J Bone Joint Surg Am 1996;78:72133.

4 Wakitani S, Kimura T, Hirooka A, Ochi T, Yoneda M, Yasui $\mathrm{N}$, et al. Repair of rabbit articular surfaces with allograft chondrocytes embedded in collagen gel. J Bone Joint Surg Br 1989;71:74-80.

5 Brittberg M, Nilsson A, Lindahl A, Ohlsson C, Peterson L. Rabbit articular cartilage defects treated with autologous Rabbit articular cartilage defects treated with autologo
cultured chondrocytes. Clin Orthop 1996;326:270-83.

6 van Susante JLC, Buma P, Schuman L, Homminga GN, van van Susante JLC, Buma P, Schuman L, Homminga GN, van
den Berg WB, Veth RPH. Resurfacing potential of heterologous chondrocytes suspended in fibrin glue in
large full-thickness defects of femoral articular cartilage: an experimental study in the goat. Biomaterials 1999;20: $1167-75$

7 O'Driscoll SW, Keeley FW, Salter RB. The chondrogenic potential of free autogenous periosteal grafts for biological resurfacing in major full-thickness defects in joint surfaces under the influence of continuous passive motion. An experimental investigation in the rabbit. J Bone Joint Surg Am 1986;68:1017-35.

8 Homminga GN, Bulstra SK, Bouwmeester PSM, van der Linden AJ. Perichondral grafting for cartilage lesions of the knee. J Bone Joint Surg Br 1990;72:1003-7.

9 Homminga GN, Bulstra SK, Kuyer R, van der Linden AJ Repair of sheep articular cartilage defects with a rabbit cosRepair of sheep articular cartilage defects with a rabbit cos-
tal perichondral graft. Acta Orthop Scand 1991;62:415tal peri.

10 Brittberg M, Faxén E, Peterson L. Carbon fiber scaffolds in the treatment of early knee osteoarthritis. A prospective 4 -year follow up of 37 patients. Clin Orthop 1994;307: 155-64.

11 Freed LE, Marquis JC, Nohria A, Emmanual J, Mikos AG Langer R. Neocartilage formation in vitro and in vivo using cells cultured on synthetic biodegradable polymers. J Biomed Mater Res 1993;27:11-23.

12 Rotter N, Aigner A, Naumann A, Planck H, Hammer C, Burmester G, et al. Cartilage reconstruction in head and neck surgery: comparison of resorbable polymer scaffolds for tissue engineering of human septal cartilage. J Biomed Mater Res 1998;42:347-56.

13 van Susante JLC, Buma P, van Osch GJVM, Versleyen D, van der Kraan PM, van den Berg WB, et al. Culture of chondrocytes in alginate and collagen carrier gels. Acta Orthop Scand 1995;66:549-56.

14 Schuman L, Buma P, Versleyen D, de Man B, van der Kraan $\mathrm{PM}$, van den Berg WB, et al. Chondrocyte behaviour within different types of collagen gel in vitro. Biomaterials $1995 ; 16: 809-14$

15 Kawamura S, Wakitani S, Kimura T, Maeda A, Caplan AI, Shino K, et al. Articular cartilage repair. Rabbit experiments with a collagen gel-biomatrix and chondrocytes cultured in it. Acta Orthop Scand 1998;69:56-62.

16 Benedetti L, Cortivo R, Berti T, Berti A, Pea F, Mazzo M, e al. Biocompatibility and biodegradation of different hyaluronan derivates (Hyaff) implanted in rats. Biomaterials $1993 ; 14: 1154-60$

17 Solchaga LA, Dennis JE, Goldberg VM, Caplan AI. Hyaluronic acid-based polymers as cell carriers for tissue-engineered repair of bone and cartilage. J Orthop Res 1999; 17:205-13.

18 Homminga GN, Buma P, Koot HWJ, van der Kraan PM, van den Berg WB. Chondrocyte behavior in fibrin gel. Acta Orthop Scand 1993;64:441-5.

19 Häuselmann HJ, Fernandes RJ, Mok SS, Schmid TM, Block JA, Aydelotte MB, et al. Phenotypic stability of
bovine articular chondrocytes after long-term culture in alginate beads. J Cell Science 1994;107:17-27.
20 Sims CD, Butler PEM, Cao YL, Casanova R, Randolpf MA, Black A, et al. Tissue engineered neocartilage using plasma derived polymer substrates and chondrocytes. Plast Reconstr Surg 1998;101:1580-5.

21 Silverman RP, Passaretti D, Huang W, Randolph MA, Yaremchuk MJ. Injectable tissue-engineered cartilage using a fibrin glue polymer. Plast Reconstr Surg 1999;103:1809-18.

22 Green WT Jr. Behaviour of articular chondrocytes in cell culture. Clin Orthop 1971;75:248-60.

23 Kuettner KE, Pauli BU, Gall G, McMemoli VA, Schenk RA. Synthesis of cartilage matrix by mammalian chondrocytes in vivo. I. Isolation, culture characteristics and morphology. J Cell Biol 1982;93:743-50.

24 Cornelissen M, Verbruggen G, Malfait AM, Veys EM, Broddelez C, De Ridder L. The study of representative populations of native aggrecan aggregates synthesized by human chondrocytes in vitro. J Tiss Cult Meth 1993;15: $139-46$.

25 Guo J, Jourdian GW, MacCallum DK. Culture and growth characteristics of chondrocytes encapsulated in alginate beads. Connect Tissue Res 1989;9:277-97.

26 Häuselmann HJ, Aydelotte MB, Schumacher BL, Kuettner KE, Gitelis SH, Thonar EJ-MA. Synthesis and turnover of proteoglycans by human and bovine adult articular chondrocytes cultured in alginate beads. Matrix 1992;12: $116-29$.

27 Maniscalco WM, Campbell MH. Alveolar type II cells synthesize hydrophobic cell-associated proteoglycans with multiple core proteins. Am J Physiol 1992;263:L34856.

28 Pearson JP, Mason RM. The stability of bovine nasal proteoglycans during isolation and storage. Biochim Biophys Acta 1977;498:176-88

29 Verbruggen G, Cornelissen M, Almqvist KF, Wang L, Elewaut D, Broddelez, et al. Influence of aging on the synthesis and morphology of the aggrecans synthesized by different human articular chondrocytes. Osteoarthritis Cartilage 2000;8:170-9.

30 Verbruggen G, Malfait AM, Veys EM, Gyselbrecht L, Lambert J, Almqvist KF. Influence of interferon-gamma on isolated chondrocytes from human articular cartilage. Dose dependent inhibition of cell proliferation and proteoglycan synthesis. J Rheumatol 1993;20:1020-6.

31 Lebarca C, Paigen K. A simple, rapid, and sensitive DNA assay procedure. Anal Biochem 1980;102:344-52.

32 Gannon JM, Walker G, Fischer M, Carpenter R, Thompson RC Jr, Oegema TR Jr. Localization of type X collagen in canine growth plate and adult canine articular cartilage. J Orthop Res 1991;9:485-94.

33 Johnson LO. Arthroscopic abrasion arthroplasty. Historical and pathological perspective: present status. Arthroscopy $1986 ; 2: 54-69$

34 Rodrigo JJ, Steadman RJ, Silliman JF, Fulstone HA. Improvement of full-thickness chondral defect healing in the human knee after debridement and microfracture using continuous passive motion. Am J Knee Surg 1994;7:109-16.

35 Stone KR, Walgenbach A. Surgical technique for articular cartilage transplantation to full-thickness cartilage defects in the knee joint. Operative Techniques in Orthopedics 1997; 7:305-11.

36 Hangody L, Kish G, Karpati Z, Szerb I, Udvarhelyi I. Arthroscopic autogenous osteochondral mosaicplasty for the treatment of femoral condylar articular defects. A preiminary report. Knee Surg Sports Traumatol Arthrosc 1997;5:262-7.

37 Mankin HJ, Doppelt S, Tomford W. Clinical experience with allograft implantation. The first 10 years. Clin Orthop 1983; 174:69-86.

38 Beaver RJ, Mahomed M, Backstein D, Davis A, Zukor DJ, Gross AE. Fresh osteochondral allografts for posttraumatic defects in the knee. A survivalship analysis. J Bone Joint Surg Br 1992;74:105-10.

39 Caplan AI, Elyaderani M, Mochizuki Y, Wakitani S, Goldberg VM. Principles of cartilage repair and regeneration. Clin Orthop 1997;342:254-69.

40 Brittberg M, Lindahl A, Nilsson A, Ohlsson C, Isaksson O, Peterson L. Treatment of deep cartilage defects in the knee with autologous chondrocyte transplantation. N Engl J Med 1994;331:889-95.

41 Paige KT, Cima LG, Yaremchuk MJ, Schloo BL, Vacanti JP, Vacanti CA. De novo cartilage generation using calcium alginate-chondrocyte constructs. Plastic Reconstr Surg 1996;97:168-78.

42 Mok SS, Masuda K, Häuselmann HJ, Aydelotte MB, Thonar EJ-MA. Aggrecan synthesized by mature bovine chondrocytes suspended in alginate. J Biol Chem 1994; 269:33021-7.

43 Bayliss MT. Metabolism of animal and human osteoarthritic cartilage. In: Kuettner KE, Schleyerbach R, Peyron G, Hascall VC, eds. Articular cartilage and osteoarthritis. New York: Raven Press, 1992:487-500.

44 Atala A, Kim W, Paige KT, Vacanti CA, Retik AB. Endoscopic treatment of vesicoureteral reflux with a chondrocyte-alginate suspension. J Urol 1994;152: 641-3.

45 Klein CPAT, van der Lubbe HBM, de Groot K. A plastic composite of alginate with calcium phosphate granulate as implant material: an in vivo study. Biomaterials 1987;8: 308-10. 
46 Suzuki Y, Tanihara M, Ohnishi K, Suzuki K, Endo K, Nishimura Y. Cat peripheral nerve regeneration across
$50 \mathrm{~nm}$ gap repaired with a novel nerve guide composed $50 \mathrm{~nm}$ gap repaired with a novel nerve guide composed of fre 75 .

47 Perka C, Spitzer RS, Lindenhayn K, Sittinger M, Schultz O. Matrix-mixed culture: new methodology for chondrocyte culture and preparation of cartilage transplants. J Biomed Mater Res 2000;49:305-11.

48 Keller J, Andreassen TT, Joyce F, Knudsen VE, Jørgensen $\mathrm{PH}$, Lucht U. Fixation of osteochondral fractures. Acta Orthop Scand 1985;56:323-6.

49 Orr TE, Patel AM, Wong B, Hatzigiannis GP, Minas T, Spector M. Attachment of periosteal grafts to articular cartilage with fibrin sealant. J Biomed Mater Res 1999;44: 308-13.
50 Petit B, Suda KM, D'Souza AL, Otten L, Pietryla D, Hartmann DJ, et al. Characterization of crosslinked collagens alginate beads: comparison of two distinct matrix compartalginate beads: comparison of two distinct

51 Silverman RP, Passaretti D, Huang W, Randolph MA, Yaremchuk MJ. Injectable tissue-engineered cartilage using a fibrin glue polymer. Plast Reconstr Surg 1999;103:1809-18.

52 Tanaka H, Matsumura M, Veliky IA. Diffusion characteristics of substrates in Ca-alginate gel beads. Biotechnol Bioeng $1984 ; 26: 53-8$

53 Marijnissen WJCM, van Osch GJVM, Aigner J, VerwoerdVerhoef $\mathrm{H}$, Verhaar JAN. Tissue-engineered cartilage using serially passaged articular chondrocytes. Chondrocytes in alginate, combined in vivo with a synthetic (E210) or biologic biodegradable carrier (DBM). Biomaterials 2000;21:571-80.

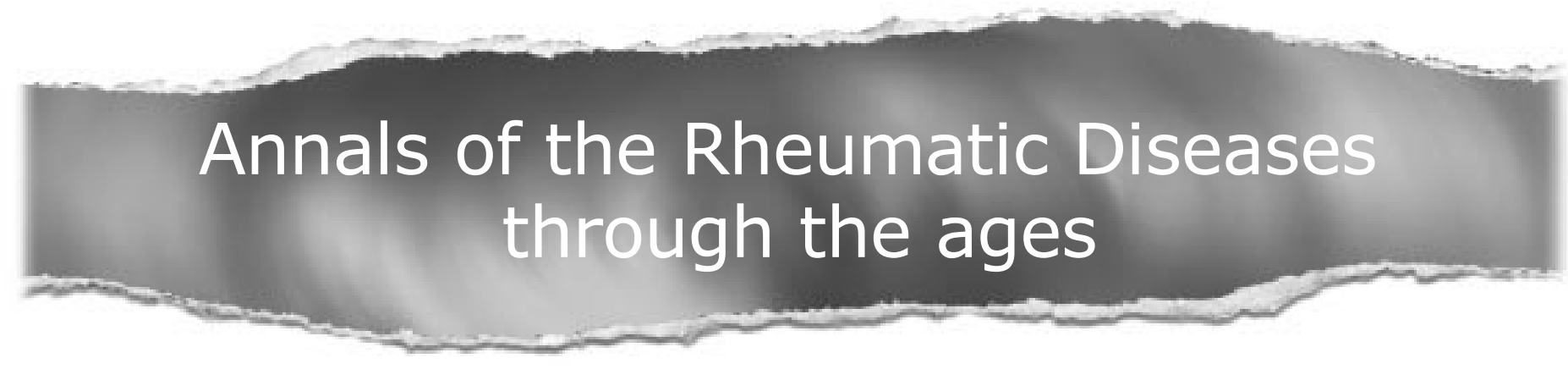

Browse the Archive

Annals of the Rheumatic Diseases online has an archive of content dating back to 1965 . Full text from 1997; abstracts from 1975; table of contents from 1965

www.annrheumdis.com 